Abstract: This paper discusses the development of a new online training course, 'A Trauma-informed approach to managing archives', for the Australian Society of Archivists. It outlines why such a course is needed, who its audience is, and provides a brief overview of what it covers. Trauma is pervasive and affects everyone, and this course provides information and training materials about what this means for archives and how archivists can better support people having a trauma reaction. It introduces the concept of trauma-informed practice, expands on that notion to outline what traumainformed archival practice may look like, and it discusses vicarious trauma and the impacts this may have on archives workers. The paper provides information about when the course will be available, and how people will be able to access it.

Keywords: online training course, trauma-informed practice, trauma-informed archival practice, vicarious trauma

\title{
A Trauma-informed approach to managing archives: a new online course ${ }^{1}$
}

Trauma is pervasive and affects us all. ${ }^{2}$ Archives are no different; they are sites of particular trauma and affect. Trauma can take many forms: people who are trauma survivors using the archives; people having a trauma reaction when reading the records held in archives; and staff being affected by the people or materials they work with (vicarious trauma). Trauma-informed practice is a set of principles and tools to deal with trauma, to normalise it, and make it part of everyday work. Recognising, and responding to the challenging material that is in records, and ensuring people - archivists and other staff, users, donors, and volunteers - are supported to provide access to these items in a sensitive and respectful way, is of increasing concern within the archival profession.

This paper discusses the creation of the Australian Society of Archivists' (ASA) 'A Trauma-informed approach to managing archives' online course, highlighting why it is needed, what it includes, who it is for, and why this is only the start of the conversation. 'A Trauma-informed approach to managing archives' is one of three new training courses to be released by the ASA in early 2020. The others are 'Indigenous Recordkeeping and Archives' and 'Out of Home Care Records'. While they stand alone, doing all three will provide a deeper understanding of the topics discussed, as they interrelate and complement each other. These courses have been developed to assist archivists, recordkeeping and information professionals in providing support to all users of the archives, with an emphasis on practical tips and advice on how to improve practice by putting people first. Specifically, the 'Traumainformed approach' course introduces the concept of trauma-informed practice, discusses why and how this can be implemented in an archival setting, introduces the concept of vicarious trauma and discusses why organisations should be aware of the risks to staff in this area.

\section{Language and Framing}

In both this discussion and the course itself, we (the authors) are conscious of the language and framing being used around this topic. We recognise that there is debate around whether words and phrases including trauma-informed, vicarious or secondary trauma are really the right words to use within the archival community. This course, and the discussion more broadly, are not meant to take away from the lived experience of trauma survivors and people with first-hand knowledge of the 
systems and policies that created the challenging and problematic records held in archives today. We acknowledge survivors' important and ongoing contributions to our profession, and their advocacy for their communities. The reason many of the discussions have used the language of trauma to date is because these are phrases that most people can immediately identify and that help to understand the serious nature of the conversation. Trauma is a powerful word, and its use may have negative connotations, or may be used to pathologize people. Some individuals and communities have identified discomfort with this terminology, feeling it enforces the use of deficit discourse or the deficit paradigm - where people or groups are represented in terms of deficiency - absence, lack, or failure. ${ }^{3}$ This is not our intention. By using this language, we increase people's ability to find other resources and relevant information on the topic, and we acknowledge the trauma and harm that may result when working in, or visiting an archive, which more generic language around affect and emotions may not. Unfortunately, so far, we have yet to come across better language to use and that is why we have used these words to frame our discussion and the course content.

\section{The need}

As mentioned above, it is now understood that trauma is pervasive and affects us all. The impacts of trauma within an archival context have begun to be recognised in the literature and at conferences. In Australia, Michaela Hart, Nicola Laurent and Cate O'Neill held a discussion session at the 2017 ASA conference entitled 'Emotional Labour and Archival Practice', ${ }^{4}$ where archivists were able to share their experiences of vicarious trauma, with some informing the presenters that it was the first time they felt comfortable doing so in a professional setting. Michaela Hart and Nicola Laurent also discussed vicarious trauma at the Society of North Carolina Archivists conference, the Archives and Records Association (UK \& Ireland) conference, and published on the topic in the Journal of the Society of North Carolina Archivists. ${ }^{5}$

In the United Kingdom, the Archives and Records Association (UK \& Ireland) created three guides about 'Emotional Support Guides For staff working with potentially disturbing materials and records', recognising the need to provide support in this area. ${ }^{6}$ In Canada, Jennifer Douglas, Katie Sloan and Jennifer Vanderfluit conducted a survey in 2016 on the topic of secondary trauma, results of which were published earlier this year and concluded with a quote highlighting the need for more resources to support archivists dealing with secondary trauma. ${ }^{7}$

The topics of vicarious trauma and trauma in the archives more broadly were also examined at the Archival Education and Research Institute in July 2019. Wendy Duff and Henria Aton presented initial findings of their 2019 survey, 'Emotional Responses and Archives: A Preliminary Survey', including the emerging themes of people being deeply affected in and by archives, while the archival field lacks the resources to tackle these problems ${ }^{8}$ At the same conference, Anna Sexton discussed how the profession could train, prepare and support recordkeepers for the traumatic potentiality of records. ${ }^{9}$ Finally, Michaela Hart and Nicola Laurent discussed the need for a trauma-informed community of practice to ensure people have support while enabling them to provide a service that centres on those with lived experience and reduces the risk of retraumatisation. ${ }^{10}$

While vicarious trauma is starting to be discussed, there has been less attention devoted to traumainformed practice within archives. Through our work on the Find \& Connect web resource we were introduced to the tandem concepts of vicarious trauma and trauma-informed practice. ${ }^{11}$ We saw many connections and parallels between trauma-informed practice and recent archival discourse, including the discussions around radical empathy and affect, about providing access to records in 
more supported and empathetic ways, ${ }^{12}$ and around working with Indigenous and other community groups to establish protocols for appropriate access. ${ }^{13}$ We saw the model of trauma-informed practice as a way to implement some of this thinking within archives, and to improve records access processes. Additionally, we were aware of a lot of important archival work happening already in this space, without it being identified as trauma-informed. Therefore, we saw an opportunity to use the language of trauma-informed practice to articulate this critical work in a more systematic framework. Through these presentations, publications, and discussions, there was increasing evidence of the need for a practical resource for archivists to use to support people managing trauma in archives. Additionally, as organisations began to recognise the issues in this area and the importance of supporting their staff, they also looked for archives-specific resources, which did not exist.

In her role on the ASA Council, Nicola Laurent was able to raise the issues of lack of support, of practical tools and of general information for archivists around trauma-informed practice and vicarious trauma, and the need for them. The ASA acknowledged this gap in the profession's resources and recognised the need to support their members and the broader profession by creating a new online course on the topic.

\section{Course content}

The 'Trauma-informed approach to managing archives' course is designed to support people working or volunteering in archives, so they feel empowered to start having conversations about traumainformed practice and vicarious trauma at the places they work; and for organisations to recognise these issues as requiring an organisational, rather than a personal response. The course covers three areas: trauma-informed practice, trauma-informed archival practice, and vicarious trauma, and it has been created as a practical resource for people in the archival and broader GLAM (galleries, libraries, archives and museum) sector. It has a mixture of written content and videos, quizzes and exercises to confirm that people understand the content and begin thinking about what some of the issues discussed mean for the organisation they work in. The emphasis is also on practical tips and tricks people can do to change their practice, backed up by a discussion of the issues and links to further reading.

\section{Trauma-informed practice}

The first section introduces the ideas behind trauma-informed practice and discusses key concepts and why it is a useful model for archives or record-holding organisations to use. Trauma-informed practice is a strengths-based approach that recognises that every interaction with someone who has had a trauma experience can either cause further harm or lead to healing. ${ }^{14}$ It comes from the medical profession, specifically psychiatrists and others working directly with trauma survivors, but now has wider applicability across the health care and other fields. It is based on five principles: Safety, Trustworthiness and Transparency, Choice, Collaboration, and Empowerment. The recentlyconcluded Royal Commission into Institutional Responses to Child Sexual Abuse recognised the need to work in a trauma-informed way, to assist survivors as they provided testimony and their stories to the Royal Commission, and so that the Commissioners and Royal Commission staff could remain safe while undertaking this difficult work. ${ }^{15}$ The first section of the course discusses the importance of these principles and the differences and reasoning behind each principle. 


\section{Trauma-informed archival practice}

The second section builds on the concepts and definitions of the first section to examine what it may mean for archives to implement a trauma-informed practice. It highlights that trauma-informed practice is a whole-of-organisation approach that does not change the core work of what is done in archives, but instead how that work and services are provided. It discusses what implementing the principles of trauma-informed practice would mean both for users and staff in an archive, and what steps archives can take to become more trauma-informed. It provides checklists of issues based on the five principles of trauma-informed practice for archives to consider about how they provide their service and what changes they may wish to make.

While an obvious area archives can implement a trauma-informed approach is the reading room or reference service, this section of the course also discusses what trauma-informed practice may mean for areas of archival practice including potential users' interactions with the building and security staff, cataloguing, finding aids and archival description, and providing access to records and records release processes. For example, archives may wish to review how minority communities have been historically described in records, and consider how that language is used in guides, finding aids and on your website today.

\section{Vicarious Trauma}

Part of trauma-informed practice is to ensure staff feel safe in their work, so that they can provide the best service to users of archives. Trauma-informed practice comes from professions where people worked directly with trauma survivors, where it soon became clear that it was necessary to support front-line workers to ensure they could continue their work with survivors in a safe and effective way. We are beginning to see a recognition of the impact of vicarious or secondary trauma within the archival profession too, as discussed above. Therefore, the third section of the toolkit discusses the impact that working with traumatic material, and working with survivors of trauma, can have on the staff in an archive. It highlights the need to take an organisational approach to issues of vicarious trauma, identifies potential triggers and symptoms of vicarious trauma, and discusses recovery pathways and resources. While highlighting that vicarious trauma is an organisational issue, this section also provides tools and approaches individuals can use if they experience vicarious trauma, and how this can become more normalised in workplace discussions.

\section{Intended audience}

The intended audience for this course is broad, as we believe that it will benefit anyone working in archives and even within the broader GLAM sector. Specific groups who we feel would benefit from this course include:

- People who work in reference roles or in frontline positions dealing directly with the public or users of an archive

- People who work with collections known to contain records documenting traumatic events, e.g. records of the Stolen Generations, out-of-home care records, police files, war records, inquest files, surveillance records etc

- Leaders and managers who want to implement change in their organisation

- Lone arrangers and others working in small archives which may be staffed by one or two people, as in these roles staff are required to undertake all aspects of archival work. 
While it was written with the Australian context in mind, this course will be equally applicable for those in other countries who are interested in these topics and looking for ideas and practical tools to help them to respond to the issues of vicarious trauma and to implement a trauma-informed approach in their archive.

\section{Conclusion}

We hope that 'A Trauma-informed approach to managing archives' is a useful early resource for the profession while we begin to understand and recognise the full impact of trauma in archives. We view this course as a starting point in opening conversations and normalising ideas around trauma, traumainformed practice and vicarious trauma, both within the profession and within individual organisations where archivists work. We hope people critically engage with the ideas the course introduces, to both keep the conversation going and to move the profession forward in this space. As a result, we hope that archivists are better able to support all who interact with archives (including ourselves) to ensure they can do so in a safe and supported way.

The course will be launched in early 2020 and information on the ASA online courses including A Trauma-informed approach, Indigenous Recordkeeping and Archives and Out-of-home care records will be available on the ASA website at the Online Courses page. ${ }^{16}$

${ }^{1}$ This is a revised and edited version of the presentation Designing a trauma-informed archive (\& archivist), Designing the Archive, Australian Society of Archivists, International Council on Archives, Archives and Records Association of New Zealand Te Huinga Mahara and the Pacific Regional Branch International Council on Archives international Conference, Adelaide, 24 October 2019.

${ }^{2}$ RD Fallot and M Harris, 'Creating Cultures of Trauma-Informed Care (CCTIC): A Self-Assessment and Planning Protocol', 2009, available at <https://www.theannainstitute.org/CCTICSELFASSPP.pdf $>$, accessed 10 November 2019.

${ }^{3}$ W Fogarty, M Lovell, J Langenberg and M_J Heron, 'Deficit Discourse and Strengths-based Approaches: Changing the Narrative of Aboriginal and Torres Strait Islander Health and Wellbeing', 2018, The Lowitja Institute, available at $<$ https://ncis.anu.edu.au/ lib/doc/ddih/Deficit Discourse and Strengthsbased Approaches FINAL WEB.pdf $>$, accessed 13 November 2019.

${ }^{4} \mathrm{M}$ Hart, $\mathrm{N}$ Laurent and C O'Neill, 'Emotional Labour and Archival Practice', paper presented at the Joint National Conference and Symposium of Australian Society of Archivists (ASA) and Information Technologies Indigenous Communities (ITIC), Melbourne, 26-28 September 2017, available at $<$ https://www.youtube.com/watch?v=RWZNGrxGs44>, accessed 20 November 2019.

${ }^{5} \mathrm{M}$ Hart and N Laurent, 'Providing an Australian Perspective on Emotional Labour and Archival Practice', paper presented at Society of North Carolina Archivists Conference, Durham, 14-16 March 2018; M Hart and N Laurent, 'Looking after the people behind the records: vicarious trauma and empathy in archival practice', paper presented at Archives and Records Association (UK \& Ireland) conference, Glasgow, 29-31 August 2018; N Laurent and M Hart, 'Emotional Labour and Archival Practice', Journal of the Society of North Carolina Archivists, vol. 15, 2018, pp. 13-22, available at $<$ http://www.ncarchivists.org/journal-of-the-society-of-north-carolina-archivists-j-snca/vol-152018/>, accessed 10 November 2019. 
${ }^{6}$ Archives and Records Association (UK \& Ireland), 'Emotional Support Guides', 2017, available at $<$ https://www.archives.org.uk/what-we-do/emotional-support-guides.html , accessed 15 November 2019

${ }^{7}$ K Sloan, J Vanderfluit and J Douglas, 'Not "Just My Problem to Handle": Emerging Themes on Archivists and Secondary Trauma', Journal of Contemporary Archival Studies, vol. 6, Article 20, 2019, available at <https://elischolar.library.yale.edu/cgi/viewcontent.cgi?article=1090\&context=jcas $>$, accessed 21 November 2019.

${ }^{8}$ W Duff, H Aton and M Shields, 'Challenges Faced by Archivists Working with Sensitive Records', paper presented at the Archival Education and Research Institute, Liverpool, 8-12 July 2019.

${ }^{9}$ Anna Sexton, 'Working with traumatic records: how should we train, prepare and support recordkeepers?', paper presented at the Archival Education and Research Institute, Liverpool, 8-12 July 2019.

${ }^{10} \mathrm{M}$ Hart and N Laurent, 'Building a Trauma Informed Community of Practice', paper presented at the Archival Education and Research Institute, Liverpool, 8-12 July 2019.

${ }^{11}$ Find \& Connect web resource, available at $<$ https://findandconnect.gov.au/ $>$, accessed 22 November 2019. While archivists might be aware of the web resource, the Find \& Connect service also includes support services in each State that assist people who grew up in out-of-home care. There is a strong counselling element to the work done by the support services, and they are required to work in a trauma-informed way, as this is recognised as best practice when working with trauma survivors.

${ }^{12}$ See for example, AJ Gilliland and M Caswell, 'Records and their imaginaries: imagining the impossible, making possible the imagined', Archival Science, vol. 16, no. 1, 2016, pp. 53-75; M Caswell and M Cifor, 'From Human Rights to Feminist Ethics: Radical Empathy in the Archives' Archivaria, vol. 81, Spring 2016, pp. 23-43, available at <https://escholarship.org/uc/item/0mb9568h $>$, accessed 10 November 2019; Department of Social Services, 'Access to Records by Forgotten Australians and Former Child Migrants: Access Principles for Records Holders, Best Practice Guidelines in providing access to records', 2015, available at $<$ https://www.dss.gov.au/families-and-children/programmesservices/family-relationships/find-and-connect-services-and-projects/access-to-records-by-forgottenaustralians-and-former-child-migrants-access-principles-for-records-holders-best-practice-guidelinesin-providing-access $>$, accessed 15 November 2019; M Caswell, 'Dusting for Fingerprints: Introducing Feminist Standpoint Appraisal', Journal of Critical Library and Information Studies, Vol. 3, 2019, available at $<$ https://journals.litwinbooks.com/index.php/iclis/article/view/113>, accessed 14 November 2019.

${ }^{13}$ S McKemmish, J Bone, J Evans, F Golding, A Lewis, G Rolan, K Thorpe and J Wilson, 'Decolonizing recordkeeping and archival praxis in childhood out-of-home Care and indigenous archival collections', Archival Science, 2019, https://dx.doi.org/10.1007/s10502-019-09321-z,; Aboriginal and Torres Strait Islander Library, Information and Resource Network Inc, 'Aboriginal and Torres Strait Islander Protocols for Libraries, Archives and Information, Services', 2005, available at $<$ https://atsilirn.aiatsis.gov.au/protocols.php >, accessed 14 November 2019; First Archivists Circle, 'Protocols for Native American Archival Materials', 2006, available at < $\underline{\text { http://www2.nau.edu/libnap- }}$ $\mathrm{p} />$, accessed 12 November 2019.

${ }^{14}$ Blue Knot Foundation, 'Trauma-informed Care and Practice', 2019, available at $<$ https://www.blueknot.org.au/Workers-Practitioners/For-Health-Professionals/Resources-for-HealthProfessionals/Trauma-Informed-Care-and-practice $>$, accessed 22 November 2019.

${ }^{15}$ Royal Commission into Institutional Responses to Child Sexual Abuse, 'Royal Commission into Institutional Responses to Child Sexual Abuse Final Report. Volume 1 'Our inquiry', 2017, available at $<$ https://www.childabuseroyalcommission.gov.au/our-inquiry $>$, accessed 12 November 2019.

${ }^{16}$ Australian Society of Archivists, 'Online Courses', available at <https://www.archivists.org.au/learning-publications/online-courses $>$, accessed 18 November 2019. 